Wright State University

CORE Scholar

Physics Faculty Publications

Physics

$5-1-2000$

\title{
ZnO Diode Fabricated by Excimer-Laser Doping
}

Toru Aoki

Yoshinori Hatanaka

David C. Look

Wright State University - Main Campus, david.look@wright.edu

Follow this and additional works at: https://corescholar.libraries. wright.edu/physics

Part of the Physics Commons

\section{Repository Citation}

Aoki, T., Hatanaka, Y., \& Look, D. C. (2000). ZnO Diode Fabricated by Excimer-Laser Doping. Applied Physics Letters, 76 (22), 3257-3258.

https://corescholar.libraries.wright.edu/physics/66

This Article is brought to you for free and open access by the Physics at CORE Scholar. It has been accepted for inclusion in Physics Faculty Publications by an authorized administrator of CORE Scholar. For more information, please contact library-corescholar@wright.edu. 


\title{
ZnO diode fabricated by excimer-laser doping
}

\author{
Toru Aoki ${ }^{\mathrm{a})}$ and Yoshinori Hatanaka \\ Research Institute of Electronics, Shizuoka University, 3-5-1, Johoku Hamamatsu 432-8011, Japan
}

David C. Look

Semiconductor Research Center, Wright State University, Dayton, Ohio 45435

(Received 31 January 2000; accepted for publication 4 April 2000)

\begin{abstract}
$\mathrm{A} \mathrm{ZnO}$ diode was fabricated by using a laser-doping technique to form a $p$-type $\mathrm{ZnO}$ layer on an $n$-type $\mathrm{ZnO}$ substrate. A zinc-phosphide compound, used as a phosphorous source, was deposited on the $\mathrm{ZnO}$ wafer and subjected to excimer-laser pulses. The current-voltage characteristics showed a diode characteristic between the phosphorous-doped $p$-layer and the $n$-type substrate. Moreover, light emission, with a band-edge component, was observed by forward current injection at $110 \mathrm{~K}$. (C) 2000 American Institute of Physics. [S0003-6951(00)02722-4]
\end{abstract}

$\mathrm{ZnO}$ has been investigated as a green fluorescent material for many years. ${ }^{1,2}$ Recently, $\mathrm{ZnO}$ has also been studied as a short-wavelength light-emitting material ${ }^{3,4}$ because it has a direct $300 \mathrm{~K}$ band gap of $3.37 \mathrm{eV}$. However, there are no reports of $p-n \mathrm{ZnO}$ diode formation because it is difficult to obtain $p$-type $\mathrm{ZnO}$. We have attempted to create $p$-type $\mathrm{ZnO}$ by excimer-laser doping of a bulk, $n$-type $\mathrm{ZnO}$ wafer, grown by the hydrothermal method. ${ }^{5}$ We have earlier reported the use of laser doping to create $p^{+}-\mathrm{ZnSe}(5$ $\times 10^{19} \mathrm{~cm}^{3}$, Hall concentration) $)^{6,7}$ and have also fabricated $p-i-n$ CdTe $\gamma$-ray detectors. ${ }^{8,9}$ In the present study, we have obtained a diode current-voltage $(I-V)$ characteristic, and have observed electroluminescence by current injection. For the $\mathrm{ZnO}$ diode, the laser doping procedure is as follows:

(1) A 35-nm-thick zinc-phosphide $\left(\mathrm{Zn}_{3} \mathrm{P}_{2}\right)$ film, as a phosphorous $(\mathrm{P})$ source, is deposited on the $\mathrm{ZnO}$ wafer by conventional vacuum evaporation.

(2) The $\mathrm{ZnO}$ wafer and $\mathrm{Zn}_{3} \mathrm{P}_{2}$ film are then exposed to $\mathrm{KrF}$ excimer-laser radiation in an ambient of high-pressure nitrogen or oxygen in order to avoid abrasion or reevaporation from the sample surface. The ultraviolet excimer laser is thought to decompose the $\mathrm{Zn}_{3} \mathrm{P}_{2}$ into $\mathrm{Zn}$ and $\mathrm{P}$ atoms, and then provide heat energy to make these atoms diffuse into the $\mathrm{ZnO}$. Then, we believe that a $\mathrm{P}$-doped $\mathrm{ZnO}$ layer is formed through the replacement of $\mathrm{O}$ atoms by $\mathrm{P}$ atoms.

Single-crystal $\mathrm{ZnO}$ wafers, which were grown by the hydrothermal method, ${ }^{5}$ were used as the substrate material. The initial $\mathrm{Zn}_{3} \mathrm{P}_{2}$ film thickness was $35 \mathrm{~nm}$, and the $\mathrm{KrF}$ excimer laser had a wavelength of $248 \mathrm{~nm}$, a pulse width of $20 \mathrm{~ns}$, and a power density of $150 \mathrm{~mJ} / \mathrm{cm}^{2}$. The irradiation chamber contained either nitrogen or oxygen at a pressure of $4 \operatorname{atm}\left(4.1 \times 10^{5} \mathrm{~Pa}\right)$.

Three different types of samples and processing, listed in Table I, were examined in this investigation. The type I and II preparations had no dopant, but were designed to determine the influence of the laser irradiation alone on the $\mathrm{ZnO}$

\footnotetext{
a) Author to whom correspondence should be addressed; electronic mail: rtaoki@ipc.shizuaka.ac.jp
}

surface. The type III processing, on the other hand, involved the $\mathrm{Zn}_{3} \mathrm{P}_{2}$ dopant material. Surface changes in the type I and II samples were studied by photoluminescence (PL) and surface $I-V$ measurements. The $I-V$ and electroluminescence measurements on the type III sample were carried out by conventional methods.

Figure 1 shows the laser-induced change in the PL spectrum of a high-resistivity $\mathrm{ZnO}$ substrate $(1 \mathrm{k} \Omega \mathrm{cm})$; the PL was excited by a $\mathrm{He}-\mathrm{Cd}$ laser at $110 \mathrm{~K}$. The untreated $\mathrm{ZnO}$ wafer has only a band-edge-emission peak, appearing at about $370 \mathrm{~nm}$ [Fig. 1(a)]. As shown in Fig. 1(b) for the type I sample, the band-edge peak decreases and a new broad peak appears at about $500 \mathrm{~nm}$ after laser irradiation in a nitrogen environment. The decrease of the band-edge intensity probably results from a deterioration of the crystallinity of the $\mathrm{ZnO}$ surface, due to the laser irradiation. On the other hand, as shown Fig. 1(c) for the type II sample, no new peaks appear in the $500 \mathrm{~nm}$ region, and the intensity of the band-edge emission does not change after excimer-laser irradiation in high-pressure oxygen. These results suggest that the peak around $500 \mathrm{~nm}$ is due to oxygen vacancies ${ }^{10}$ formed by the high-temperature excimer-laser radiation, and that the high-pressure oxygen environment suppresses the formation of oxygen vacancies at the $\mathrm{ZnO}$ surface. The surface resistivity was not changed after excimer-laser irradiation in high-pressure oxygen, but was drastically reduced, evidently through donor formation, when irradiated in a high-pressure nitrogen ambient. This result can be explained by the expected donor nature of oxygen vacancies in $\mathrm{ZnO}$, and the suppression of such vacancies by annealing in an oxygen environment.

The $I-V$ characteristics of the $\mathrm{ZnO}$ diode fabricated using a low-resistivity $(0.2 \Omega \mathrm{cm})$ substrate (type III sample) are shown in Fig. 2. The electrodes were placed between the $\mathrm{P}$-doped $\mathrm{ZnO}$ layer and the $n$-type $\mathrm{ZnO}$ substrate. These

TABLE I. Samples and processing employed in this study.

\begin{tabular}{cccc}
\hline \hline Type & Dopant source & Environment & Substrate resistivity \\
\hline I & $\ldots$ & Nitrogen & High \\
II & $\ldots$ & Oxygen & High \\
III & $\mathrm{Zn}_{3} \mathrm{P}_{2}$ & Oxygen & Low \\
\hline \hline
\end{tabular}




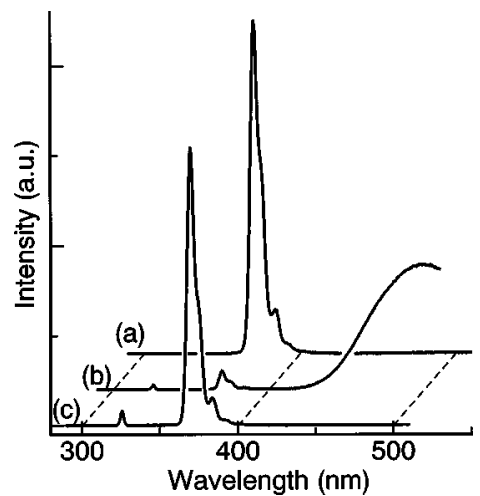

FIG. 1. Photoluminescence spectra from a $\mathrm{ZnO}$ wafer: (a) untreated; (b) after excimer-laser irradiation in a high-pressure nitrogen environment (type I); and (c) in a high-pressure oxygen environment (type II). The spectra were excited by a $\mathrm{He}-\mathrm{Cd}$ laser $(325 \mathrm{~nm})$ at $110 \mathrm{~K}$.

characteristics show that a $p-n$ diode can be fabricated. An attempt to prove the $p$-type nature of the P-doped layer by Hall measurements was not successful. However, the data obtained were confirmed $p$-type, though the carrier concentrations could not be decided because of their considerable fluctuation. This is considered to be a result of the doped layer being very thin $(\sim 50 \mathrm{~nm}),{ }^{11}$ and of the very low measurement currents which limit the Hall measurement. The graph in Fig. 2 (see the inset) shows surface $I-V$ characteristics using two gold electrodes on the P-doped layer. For linear dependences of $I-V$ characteristics, the Ohmic contact between the P-doped layer and gold electrode are fairly confirmed. After laser irradiation, the residual $\mathrm{Zn}_{3} \mathrm{P}_{2}$ layer was not observed from surface analysis, such as Auger electron spectroscopy and x-ray photoelectron spectroscopy.

Figure 3 displays the electroluminescence spectrum and photographs of the light output for a $\mathrm{ZnO}$ diode at $110 \mathrm{~K}$. The diode was operated under the following conditions: temperature, $110 \mathrm{~K}$; current density, about $30 \mathrm{~A} / \mathrm{cm}^{2}$ [Fig. 3(a)] or $10 \mathrm{~A} / \mathrm{cm}^{2}$ [Fig. 3(b)]; and bias voltage, $18.4 \mathrm{~V}$ [Fig. 3(a)] or $10.1 \mathrm{~V}$ [Fig. 3(b)]. The light emission was weak, but a white-violet color was clearly observable. The spectrum, although noisy, includes a peak at about $370-380 \mathrm{~nm}$, attrib-

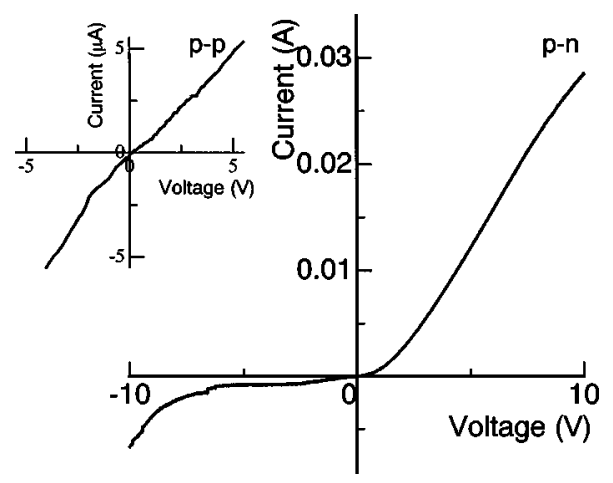

FIG. 2. Current-voltage characteristics for a $\mathrm{ZnO}$ diode formed by a P-doped layer on an $n$-type substrate (type III sample); the substrate had a resistivity of $0.2 \Omega \mathrm{cm}$. The inset shows surface current-voltage characteristics on the P-doped layer measured with two gold electrodes on the surface.

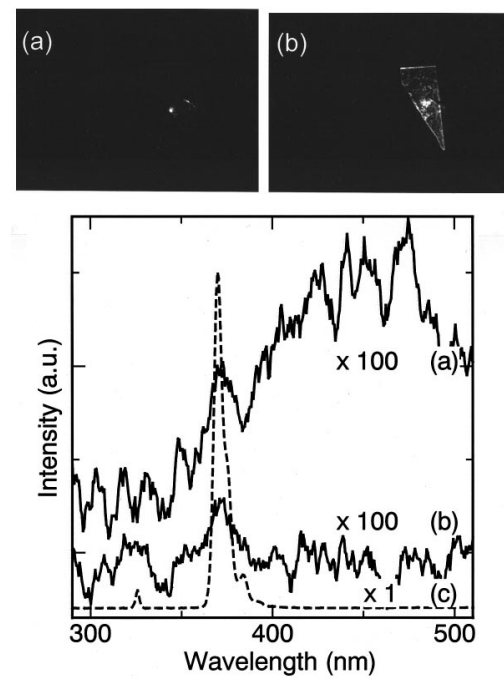

FIG. 3. Photographs of light output and electroluminescence spectra of a $\mathrm{ZnO} p-n$ diode operated at $110 \mathrm{~K}$, and (a) $30 \mathrm{~A} / \mathrm{cm}^{2}$ (18.4 V bias) or (b) 10 $\mathrm{A} / \mathrm{cm}^{2}$ (10.1 V bias) of current injection. (c) Photoluminescence spectrum of the same sample, as a reference.

uted to band-edge emission, and a band in the 400-600 nm region.

In summary, we have fabricated a $\mathrm{ZnO}$ diode by using laser phosphorus doping to form a $p$-type $\mathrm{ZnO}$ layer on an $n$-type $\mathrm{ZnO}$ substrate. A diode $I-V$ characteristic was obtained in this structure, and white-violet electroluminescence was observed at $110 \mathrm{~K}$. The spectrum includes a peak at about $370-380 \mathrm{~nm}$, attributed to band-edge emission, and a broad peak in the region of $400-500 \mathrm{~nm}$, evidently due to defect states.

This work was partly supported by a Grant-in-Aid for Scientific Research (B) of the Japanese Government. One of the authors (D.C.L.) was supported under U.S. Air Force Contract No. F33615-95-C-1619, which includes funding from the Air Force Office of Scientific Research.

${ }^{1}$ P. H. Kasai, Phys. Rev. 130, 989 (1963).

${ }^{2}$ K. Vanheusden, W. L. Warren, C. H. Seager, D. R. Tallant, J. A. Voigt, and B. E. Gnade, J. Appl. Phys. 79, 7983 (1996).

${ }^{3}$ A. Yamamoto, T. Kido, T. Goto, Y. Chen, T. Yao, and A. Kasuya, Appl. Phys. Lett. 74, 469 (1999).

${ }^{4}$ P. Zu, Z. K. Tang, G. K. L. Wong, M. Kawasaki, A. Ohtomo, H. Koinuma, and Y. Segawa, Solid State Commun. 103, 459 (1997).

${ }^{5}$ M. Suscavage, M. Harris, D. Bliss, P. Yip, S-Q. Wang, D. Schwall, L. Bouthillette, J. Bailey, M. Callahan, D. C. Look, D. C. Reynolds, R. L. Jones, and C. W. Litton, MRS Internet J. Nitride Semicond. Res. 4S1, G3.40 (1999).

${ }^{6}$ Y. Hatanaka, T. Aoki, T. Arakawa, D. Noda, and Y. Nakanishi, J. Cryst. Growth 184/185, 425 (1998).

${ }^{7}$ T. Aoki, H. Yamamoto, Y. Aoki, Y. Nakanishi, and Y. Hatanaka, Proceedings of the 2nd International Symposium on Blue Laser and LightEmitting Diodes (1998), p. 78.

${ }^{8}$ Y. Hatanaka, M. Niraula, Y. Aoki, T. Aoki, and Y. Nakanishi, Appl. Surf. Sci. 142, 227 (1999).

${ }^{9}$ D. Mochizuki, M. Niraula, T. Aoki, Y. Tomita, T. Nihashi, and Y. Hatanaka, Nucl. Instrum. Methods Phys. Res. A 436, 127 (1999).

${ }^{10}$ K. Vanheusden, C. H. Seager, W. L. Warren, D. R. Tallant, and J. A. Voigt, Appl. Phys. Lett. 68, 403 (1996).

${ }^{11}$ D. Mochizuki, M. Niraula, T. Aoki, T. Nagai, M. Kinoshita, and Y. Hatanaka, J. Cryst. Growth (in press). 